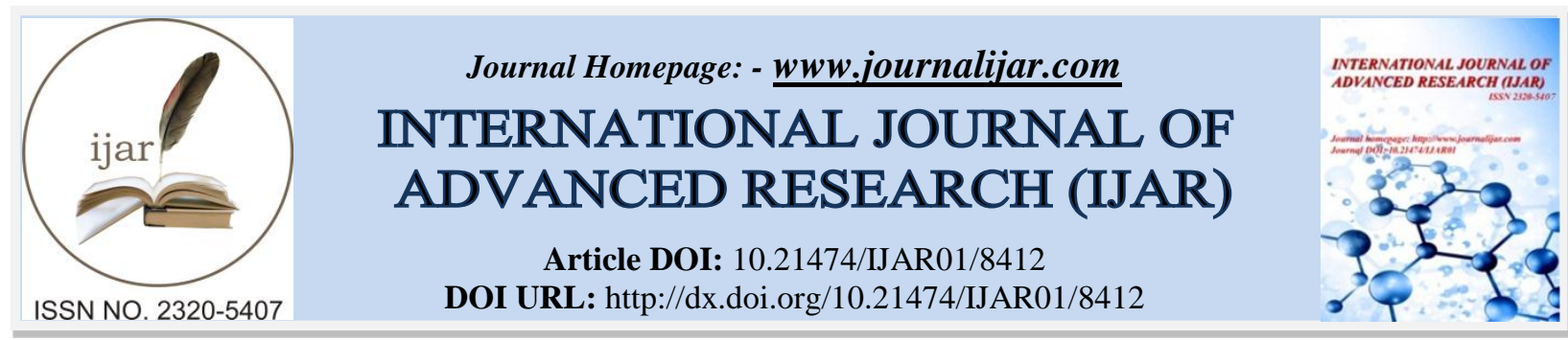

RESEARCH ARTICLE

\title{
PREVALENCE OF ROTAVIRAL GASTROENTERITIS AMONG CHILDREN LESS THAN 2 YEARS WITH DIARRHOEAL DISEASES IN A TERTIARY CARE HOSPITAL.
}

\author{
S.Senthamarai ${ }^{1}$, S.Sivasankari ${ }^{2}$, C.Anitha ${ }^{3}$, V.M. Somasunder ${ }^{3}$, K.Akila ${ }^{3}$, V.J.Shuba ${ }^{3}$, S.Siji Mol ${ }^{4}$ and \\ K.Muthulakshmi ${ }^{5}$. \\ 1. Professor, Department of Microbiology, Meenakshi Medical College \& Research Institute. Kanchipuram. \\ 2. Associate Professor, Department of Microbiology, Meenakshi Medical College \& Research Institute. \\ 3. Assistant Professor, Department of Microbiology, Meenakshi Medical College \& Research Institute. \\ 4. Tutor, Department of Microbiology, Meenakshi Medical College \& Research Institute. \\ 5. Professor\& HOD, Department of Microbiology, Meenakshi Medical College \& Research Institute. \\ Kanchipuram.
}

\section{Manuscript Info}

Manuscript History

Received: 14 November 2018

Final Accepted: 16 December 2018

Published: January 2019

Key words:-

Rotaviral gastroenteritis, Diarrhoea, surveillance.

\section{Abstract}

Background: Acute Gastroenteritis (diarrhoeal disease) is the second most common cause of death among children below 5 years and it remains a major public health concern

Aim: This study was done to study the prevalence rate of rotavirus infection in children upto two years presenting with diarrhoea.

Materials and method: This study was conducted in our tertiary care hospital, Meenakshi Medical College \& Research Institute (MMCH \& RI), Kanchipuram, Tamilnadu. The study period was from September 2016 to December 2017. A total of 152 stool samples were collected from children less than 2 years with acute diarrhoea in paediatric department.

Result and discussion: In our study, out of 152 stool samples tested, 40 were positive for rotavirus (26.3\%). Among the positive patients 26 were male $(65 \%)$ and 14 were female $(35 \%)$. This is more common in children of age group between 6-18 months (87.5\%).

Conclusion: In our study, the burden of rotaviral associated diarrhoea in children under 2 years is $26.3 \%$ and male were commonly affected and prevalent among 6-18 months old children. Health education, regular surveillance and rotavirus vaccination will reduce deaths among children younger than five years.

Copy Right, IJAR, 2018,. All rights reserved.

\section{Introduction:-}

Acute Gastroenteritis (diarrhoeal disease) is the second most common cause of death among children below 5 years and it remains a major public health concern and frequent cause of morbidity both in developed and developing countries. [1]. On the basis of Global surveillance network and hospital based studies, reported prevalence rate of diarrhoeal diseases due to Rotavirus is between 6 to $56 \%$ of among children under 5 years of age.[2] In India, among 2.3 million annual deaths in children, about 334000 are attributable to diarrhoeal diseases. Children

Corresponding Author:-S.Senthamarai.

Address:-Professor, Department of Microbiology, Meenakshi Medical College \& Research Institute. Kanchipuram. 
younger than five years died from rotavirus infection in India in 2005, with mortality rate of 4.14 deaths per 1000 live births (i.e) 1 child in 242 will die from rotavirus infection by the age of 5 years.[3]

Acute Gastroenteritis (AGE) is caused by bacterial, viral and parasitic agents. Among the viral, rotavirus plays a predominant role in causing AGE in children under 5 years. It belongs to family Reoviridae and has 5 species A,B,C,D \& E. [4] It is contagious and transmitted easily by feco-oral route via contact with contaminated hands, surfaces and objects [5]. The infections caused by rotaviruses varies from asymptomatic to life threatening diarrhoeal diseases and death which is often due to severe dehydration. [6].The most common risk factors with rotaviral diarrhoea are socio economic, sanitation and nutritional status, early complimentary feeding, dehydration, vaccination status and age less than 2 years [7]

The first year of life is the period of highest risk for death in rotaviral AGE. To match with the magnitude of the problem, the real statistics not documented, because in many health care setup especially in rural, most of the diarrhoeal diseases are not screened routinely for rotaviruses.

With this view, we conducted this study to know the prevalence of rotaviral diarrhoea among children under 2 years in our locale.

\section{Materials and method:-}

This study was conducted in our tertiary care hospital, Meenakshi Medical College \& Research Institute (MMCH \& RI), Kanchipuram, Tamilnadu. The study period was from September 2016 to December 2017. A total of 152 stool samples were collected from children less than 2 years with acute diarrhoea in paediatric department. Children less than 2 years with acute gastroenteritis enrolled in the present study was defined as the passage of $\geq 3$ loose or watery stools a day with or without associated symptoms such as vomiting, fever and abdominal pain were included in this study [8,9] . Demographic data were recorded for all the patients. Children who were not willing to participate in the study, dysentery cases and not suffering from diarrhea were excluded from the study. Ethical clearance was obtained from the Institutional Ethical Committee.

The stool samples were collected in clean, wide mouthed sterile container and transported to the lab immediately after proper labelling done. All the samples were taken for test within 30 minutes to one hour of collection. In case of delay for analysis, the samples were stored at $-20^{\circ} \mathrm{C}$ until analyzed.

\section{Test method}

Rotavirus antigen detection by ELISA - Principle: It is a solid phase sandwich type ELISA in which microtitre wells are coated with monoclonal antibody directed against group specific antigen of human Rotaviruses. Positive and negative control and faecal specimens were added to the wells and incubated with an anti-Rotavirus monoclonal antibody conjugated to horseradish peroxidase. After 60 minutes incubation at room temperature, the sample well is washed in order to remove unbound enzyme labeled antibodies. Enzyme substrate A (urea peroxide) and substrate B Tetra Methyl Benzidine (TMB) are added to the wells and incubated for 10 minutes at room temperature. The enzyme bound in the wells converts the colorless substrate to blue colour. The intensity of the blue colour is directly proportional to the concentration of Rotavirus antigen in the sample. After adding stop solution the colour converted from blue to yellow and read spectrophotometrically using a 450nm filter.

\section{Results:-}

In our study, out of 152 stool samples tested, 40 were positive for rotavirus (26.3\%) (Table-1). Among the positive patients 26 were male and 14 were female ( Figure-1). Among this 40 positive rotaviral diarrhoeal cases, age distribution were recorded as follows: 0-6 months, 7-12 months, 13-18 months and 19-24 months. (Table-2)

Table 1:-Distribution of rotaviral infected stool sample

\begin{tabular}{|c|c|c|}
\hline $\begin{array}{l}\text { Total number of stool samples } \\
\text { tested }\end{array}$ & Positive for rotaviral infection & Percentage \\
\hline 152 & 40 & 26.3 \\
\hline
\end{tabular}




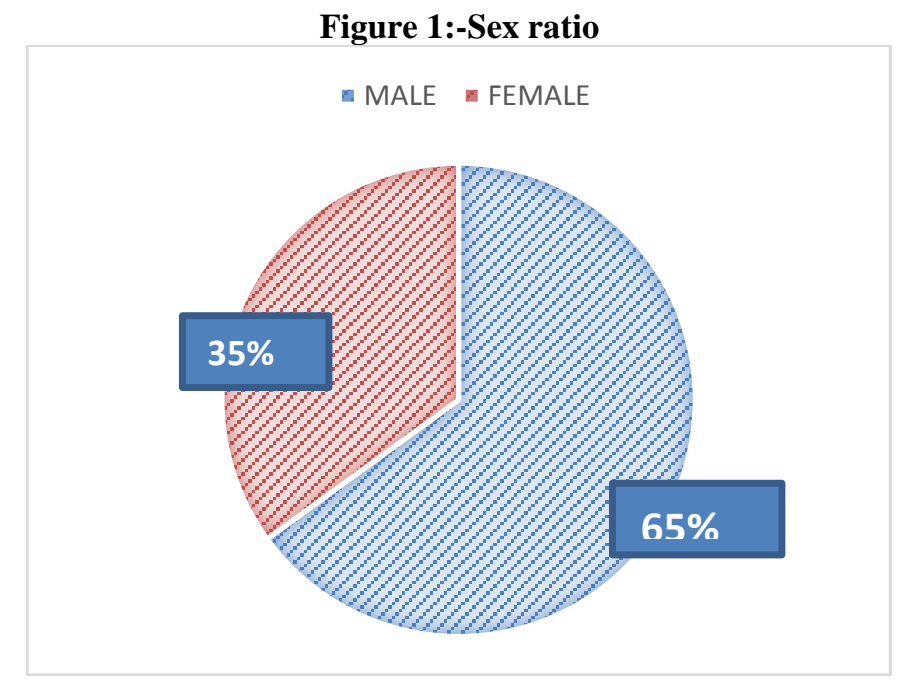

Table 2:- Age and sex distribution of rotaviral positive cases

\begin{tabular}{|l|l|l|l|l|}
\hline $\mathrm{N}=40$ & $0-6$ months & $7-12$ months & $13-18$ months & $19-24$ months \\
\hline Male $\quad(n=26)$ & 3 & 18 & 5 & 1 \\
\hline Female $(n=14)$ & 1 & 8 & 4 & 0 \\
\hline & $4(10 \%)$ & $26(65 \%)$ & $9(22.5 \%)$ & $1(2.5 \%)$ \\
\hline
\end{tabular}

\section{Discussion:-}

The burden of rotaviral diarrhoea in children is a major public health concern.

In our study the prevalence rate of rotaviral diarrhoea in children less than 5 years is $26.3 \%$. Similar percentages of results were reported with Saravanan et al, WgCdr B.M. John et al, Shetty et al, Manohar et al., Their reported prevalence rates were $22.6 \%, 24 \%, 25.66 \%$ and $28.57 \%$ respectively $[10,11,12$. Our study is in line with these studies.

Various reports about the prevalence of rotaviral AGE, from India ranging from 4\% to 62.6\%. [13] [Phareen et al] (r-10). Slightly lower percentages of prevalence were reported in the studies of Christabel et al (13.1\%), Muendo et al $(14.5 \%)$ \& Manick Dass et al (18.3\%)[14,2,15]. Decline in the rate could be attributed to increased awareness about disease transmission, illness and preventive measurements through education by health care personnel to the public. Whereas $51 \%$ was the prevalence rate for rotaviral diarrhoea reported in the study of Babji.S et al in Nagercoil [16]. Many published reports revealed that the prevalence in Turkey is 39\%, England 43\%, Vietnam 50\%, Poland $41 \%$, and $45 \%$ in Kuwait.

The wide variation of the prevalence rate can be attributed to vaccination status of the child and community, differences in age groups studied, socio economic, sanitation and nutritional status, method used for diagnosis, serotype exist in that geographical location and the seasonal variation of virus strains.

In this study, male children (65\%) were commonly infected than female $(35 \%)$. Male preponderance was reported with the studies of Tehereh et al, Samuel et al and Magzoub et al.[17,18,19] In relation to gender, the results obtained here agree with these studies with significant difference between genders with higher positivity rates among males. The prevalence in both male and female children was same in the report of Kurugol et al., and Chavan et al.[20,21] 
Though all age groups are affected by rotavirus infection, the infection is more vulnerable in children below 5 years of age especially in the first year of their life. Our study is concordant with this. More number of children got infection between 6 to 18 months.

According to various reports, rotavirus infections are more commonly observed between 6 -24 months of age. Less number of cases $(10 \%)$ are seen in the age group less than 6 months.[2,6,13] This could be due to the presence of protective maternal antibodies and exclusive breast feeding. 2.5\% of children were between 18-24 months. This less number could be explained with the exposure to rotavirus and consequent acquisition of immunity.

Although Rotavirus vaccine is available in India, complete data on who is being vaccinated are not available. Many data indicate that if rotavirus vaccine were delivered as part of a National Programme, deaths among children younger than five years could be prevented. This would make rotavirus vaccine a valuable component of India's strategy to reduce childhood mortality. [3]

\section{Conclusion:-}

Rotavirus causing diarrhoeal diseases are the major cause of mortality and morbidity in children under five and economic burden to health care system and society. Regular surveillance for rotaviral screening and molecular analysis will help to know the epidemiological pattern and real magnitude of the problem. The availability of rapid tests like Latex Agglutination Test, Immuno chromatography and ELISA helps to screen, diagnose and treat the case most effectively. The most effective method to prevent and to reduce Rotaviral disease burden is the health education about viral transmission and preventive measures, vaccination.

\section{References:-}

1. Sae Satish Pol, Ashwini Kacharu Dedwal, Sujata Sudhir Ranshing, Shobha Dattatray Chitambar, Sushma Narayan Pednekar, Renu Satish Bharadwaj. Prevalence and characterization of rotaviruses in children hospitalized for diarrheal disease in a tertiary care hospital, Pune ; Indian Journal of Medical Microbiology Volume 35 ; Issue 1 ; January-March 2017

2. Muendo1, Ahmed Laving, Rashmi Kumar, Boniface Osano, Thaddaeus Egondi and Pamela Njuguna. Prevalence of rotavirus infection among children with acute diarrhoea after rotavirus vaccine introduction in Kenya, a hospital cross-sectional study Catherine BMC Pediatrics (2018) 18:323 https://doi.org/10.1186/s12887-018-1291-8

3. Bulletin of the World Health Organization' Past issues Volume 90: 2012 Volume 90, Number 10, October 2012, 713-792.

4. Dennehy, P.H. 2000. Transmission of rotavirus and other enteric pathogens in the home. Pediatric. Infect. Dis. J., 19(10 Suppl): 103-105.

5. Butz, A.M.., Fosarelli, P., Dick, J., Cusack, T., Yolken, R., Prevalence of rotavirus on high - risk fomites in day-care facilities, Paediatrics, 1993, 92 (2), 202-5.

6. WgCdr, B.M. John, Col Amit Devgan, Maj BarnaliMitra. 2014. Prevalence of rotavirus infection in children below two years presenting with diarrhea. Med. J. Armed Forces India, 70: 116-119.

7. Nakawesi J, Wobudeya E, Ndeezi G, Mworozi E. Prevalence and factors associated with rotavirus infection among children admitted with acute diarrhea in Uganda. BMC Pediatr. 2010;10(69): 1-5.

8. Freedman SB, Ali S, Oleszczuk M, Gouin S, Hartling L. Treatment of acute gastroenteritis in children: An overview of systematic reviews of interventions commonly used in developed countries Evid.-Based Child Health. 2013;8:11231137.

9. JAWETZ, MELNICK, \& ADELBERG.(2013).Medical Microbiology. Reoviruses, Rotaviruses, and Caliciviruses.26thedition.New York:McGraw-Hill. 30

10. Saravanan et al.(2004) Rotavirus infection among infants and young children in Chennai, south India. Indian Journal of Medical Microbiology. 22 (4/Oct).p.212-221.

11. Shetty, et al. (2014) Rotavirus and Adenovirus diarrhoea in children. Muller Journal of Medical Science and Research. 5 (2/Jul - Dec).p.143-148.

12. Manohar, et al. (2015) Prevalence of Rotavirus diarrhoea among under-5 hospitalized children in a Government Tertiary Hospital, Tirupati. Journal of Dr. NTR University of Health Sciences.4(2).p. 112-116

13. Phareen K. Khatib, Zia H. Khan *, Prevalence of Rotavirus Diarrhoea among Childrens in Akola. International Journal of Pharmaceutical Research \& Allied Sciences. Volume 2, issue 1 (2013),65-69 
14. Christabel, C.E., Kwamena, W.C., Hope, G., Richard, H.A., Julius, A.M., George, E.A. 2012. Prevalence of severe acute rotavirus gastroenteritis and intussusceptions in Ghanaian children under 5 years of age. J. Infect. Dev. Ctries, 6(2): 14-155

15. S. Manick Dass1, Snigdha Pattnaik2*, A study on prevalence of rotavirus infection in children below 5 years, with acute gastroenteritis K. Amulya3 International Journal of Community Medicine and Public Health Dass SM et al. Int J Community Med Public Health. 2018 Aug;5(8):3358-3361

16. S Babji, R Arumugam, A Peters, $\mathrm{S}$ Ramani, ${ }^{*} \mathrm{G}$ Kang Detection and characterisation of rotaviruses from children less than 5 years hospitalised with acute gastroenteritis in Nagercoil ; Indian Journal of Medical Microbiology, (2013) 31(1): 69-71

17. Tehereh, Z.K., Ahmed, S., Gholamreza, K., Manoochehr, M. 2013. Relative Frequency of Rotavirus and Adenovirus among Children Aged 160 Months Hospitalized With Acute Diarrhea in South Western Iran. Jundishapur J. Microbial., 6(1): 47-50.

18. Magzoub, A.M., Naser, E.B., Jalal, A.B., Omran, F.O. 2013. Rotavirus infection among Sudanese children younger than 5 years of age: a cross sectional hospital-based study. Pan African Med. J., 16: 88

19. Samuel O. Oyinloye1*, John Idika1, Mahdi Abdullahi1, Mohammed A. Lawan2, Abdulrazak Dahiru3 and Aisha Salihu1,4, Prevalence of Rotavirus Infection in Infants and Young Children with Gastroenteritis in Two North-East States, Nigeria. British Journal of Medicine \& Medical Research 20(2): 1-7, 2017; Article no.BJMMR. 22773

20. Kuruqol, Z .et al. (2003) Rotavirus gastroenteritis among children under five of age in Izmir, Turkey. Turkey $\mathbf{J}$ pediatrics. 45(4 / Oct-Dec).p.290-4.

21. Chavan, C. et al. (2013) Prevalence of rotavirus diarrhoea among children hospitalized in a tertiary care hospital in Western India. Int J Pharm Biomed Sci .4(1).p.4-7.

22. Sai et al.(2013) Epidemiology and clinical features of rotavirus and norovirus infection among children in Ji'nan, hina. Virology Journal, [online].10.p.302.Available from http://www.virologyj.com/content/10/1/302. [accessed on 19/06/2015]. 